\title{
Effects of time, sex, ethnic origin, and area of residence on prevalence of asthma in Israeli adolescents
}

\author{
Arie Laor, Leon Cohen, Yehuda L Danon
}

\begin{abstract}
Objectives-To study effects of time, sex, ethnic origin, and area of residence on prevalence of asthma in Israeli adolescents.

Design-Retrospective survey of asthma from computerised medical draft records of conscripts examined up to the end of 1989.

Setting-Five regional centres in Israel.

Subjects-443186 conscripts (262836 males and 180350 females) aged 17-18 who were born over a nine year period.
\end{abstract}

Main outcome measures-Asthma determined by medical history, physical examination, and lung function tests at rest and after exercise.

Results-Asthma was more prevalent in males than females $(26 \cdot 5 / 1000 v 21 \cdot 4 / 1000$, relative risk $1 \cdot 25$ (95\% confidence interval $1 \cdot 19$ to $1 \cdot 32)$ ). Subjects were split into three groups according to year of birth, and prevalence of asthma increased over time from $18 / 1000$ to $24 / 1000$ to $36 / 1000$ (risk of asthma $0.56(0.54$ to 0.59$)$ for first birth group relative to last birth group and $0.69(0.66$ to 0.72$)$ for second group relative to last group). Risk of asthma was also affected by ethnic origin (highest for Western origin and lowest for north African origin, relative risk 1.63 $(1.56$ to 1.71$)$ ) and area of residence (highest in the central coastal region-risk of $1.24(1.19$ to 1.30$)$ relative to the north coastal region-and lowest in inland areas-risk of $0.67(0.64$ to 0.70$)$ relative to north coastal region).

Conclusions-Prevalence of asthma in Israel is increasing and is higher in males, in people of Western origin, and in those living in the most industrialised coastal region.

\section{Introduction}

Asthma is a leading cause of chronic disease in young adults, and there is some evidence that its frequency and severity are increasing. ${ }^{1}$ This is difficult to assess confidently, however, because of a lack of reliable figures from population studies that used uniform diagnostic criteria. ${ }^{2}$ Few studies have been made of large cohorts $^{3-5}$ and fewer still have been based on nearly a whole population. ${ }^{6}$

Our study made use of the database of conscripts of the Israeli Defense Force. This information allowed us to investigate the prevalence of asthma, based on uniform diagnostic criteria, among nearly all the Jewish population aged 17-18 in Israel over a decade. Thus any changes that we found could not be due to different diagnostic criteria or biased by sample selection. The data also allowed us to evaluate the effect of ethnic origin, demographic variations, sex, and time on the prevalence of asthma.

\section{Subjects and methods}

We examined the records of 443186 subjects, more than $95 \%$ of Jewish males and $80 \%$ of Jewish females aged 17-18 in Israel who were born over nine years. The characteristics of the computerised database which held these records have been described. ${ }^{7}$ The study population had completed their medical draft examination by the end of 1989 . During this examination the subjects had been asked whether they had ever been diagnosed as having asthma, and whether they suffered from recurrent wheezing, nocturnal cough, or wheeze after exertion. All subjects who had reported one or more of the above symptoms in the three years before the examination were referred for examination by a pulmonologist.

The examination by the pulmonologist included a detailed medical history, physical examination, and spirometry at rest. Normal spirometry at rest was defined as a forced expiratory volume in one second of more than $70 \%$ of the predicted value. All subjects, except those with overt clinical signs and spirometric evidence of severe airway obstruction, also performed an exercise test. This included running at $5 \mathrm{~km} / \mathrm{h}$ on a treadmill inclined at $10^{\circ}$ for six minutes while breathing room air $\left(22^{\circ} \mathrm{C}, 50 \%\right.$ relative humidity). Lung function was measured at five and 10 minutes after completion of the exercise test, and the percentage fall in forced expiratory volume in one second was determined. Asthma was diagnosed in subjects who required regular antiasthmatic treatment; had a history of one or more of the symptoms related to asthma in the three years before the examination; or had a forced expiratory volume in one second that was less than $70 \%$ of the predicted value at rest or that fell by more than $10 \%$ after exercise.

\section{CLASSIFICATION OF SUBJECTS}

The conscripts were divided into three groups by their birth year (each group covered three years but exact dates cannot be given for reasons of national security) and into four ethnic groups based on their fathers' or grandfathers' (if the father was Israeli born) country of birth. The ethnic groups were Israeli (conscript, father, and grandfather born in Israel), Western (conscript, father, or grandfather born in Europe, America, or South Africa), Asian (conscript, father, or grandfather born in an Asian country), and north African (conscript, father, or grandfather born in north Africa). The examinations had been made in five regional centres, and since $98.5 \%$ of the conscripts had been examined in their local regional centre they could be divided into five groups by their area of residence. The regional centres were Tel-Aviv (the central coastal area; industrialised, hot, and relatively humid), Haifa (the northern coastal area; industrialised but less hot and humid), Jerusalem (a mountainous inland area; less populated and industrialised and relatively dry), south (mainly the Negev desert; sparsely populated and less industrialised), and Tiberias (an inland rural area; not densely populated and hot and dry).

\section{STATISTICAL ANALYSIS}

We computed raw prevalence of asthma in subgroups. Logistic modelling was used to study the interaction and relative risk of the epidemiological factors. In the logistic models the dependent variable, 
asthma, received a value of 0 for conscripts with no asthma and 1 for conscripts with asthma. The independent variables were dummy variables defining the variables detailed in the methods section (sex, time of birth, ethnic origin, and regional centre). As proposed by McCullagh and Nelder, ${ }^{8}$ we used the deviance as our generalised measure of discrepancy in a series of nested logistic models progressively simplified.

Using this strategy we produced parsimonious models for the data in which terms that were not necessary were excluded. A difference of less than three in deviance between two nested models with one degree of freedom difference was used as the criterion for simplification. The results of the final logistic models are presented as adjusted odds ratios (adjusted relative risk for asthma relative to the missing categories) with their corresponding $95 \%$ confidence intervals. The models were computed by using the IRLS algorithm and the logistic procedure provided by SAS $6 \cdot 04 .^{9}$

\section{Results}

We studied the records of 262836 male conscripts and 180350 females (orthodox Jewish females are not required to undergo draft examinations) of whom $30 \%$ (81 599 males and 53264 females) were in the first birth group, 33\% ( 85455 males and 59036 females) were in the second group, and 37\% (95782 males and 68050 females) were in the third group; $7 \%$ (20 699 males and 10201 females) were of Israeli origin, 38\% (94998 males and 72812 females) were of Western origin, 28\% (73 169 males and 50617 females) were of Asian origin (mainly from the Middle East), and 27\% (73 970 males and 46720 females) were of north African origin; and $48 \%$ (120575 males and 90631 females) attended the Tel-Aviv centre, $21 \%$ ( 56440 males and 37366 females) attended the Haifa centre, 11\% (30324 males and 16842 females) attended the Jerusalem centre, $12 \%$ ( 31545 males and 20893 females) attended the south centre, and 7\% (19632 males and 12356 females) attended the Tiberias centre. The prevalence of asthma

TABLE 1-Prevalence of asthma among 262836 male adolescents by time of birth, ethnic origin, and area of residence. Values are prevalence per 1000 subjects (numbers of subjects)

\begin{tabular}{|c|c|c|c|c|c|}
\hline \multirow[b]{2}{*}{$\begin{array}{l}\text { Area of } \\
\text { residence }\end{array}$} & \multicolumn{5}{|c|}{ Ethnic origin } \\
\hline & Israeli & Western & Asian & $\begin{array}{l}\text { North } \\
\text { African }\end{array}$ & Total \\
\hline \multicolumn{6}{|c|}{ First birth period } \\
\hline $\begin{array}{l}\text { Tel-Aviv } \\
\text { Haifa } \\
\text { Jerusalem } \\
\text { Tiberias } \\
\text { South }\end{array}$ & $\begin{array}{c}28(50 / 1785) \\
15(29 / 1999) \\
19(23 / 1227) \\
6(5 / 850) \\
25(5 / 198)\end{array}$ & $\begin{array}{l}31(454 / 14867) \\
25(165 / 6479) \\
18(55 / 3001) \\
22(34 / 1573) \\
16(37 / 2365)\end{array}$ & $\begin{array}{c}19(271 / 14600) \\
13(38 / 2839) \\
10(29 / 2811) \\
7(7 / 1043) \\
11(22 / 1990)\end{array}$ & $\begin{array}{c}13(111 / 8596) \\
9(48 / 5064) \\
8(17 / 2240) \\
7(16 / 2373) \\
5(30 / 5458)\end{array}$ & $\begin{array}{c}22(886 / 39848) \\
17(280 / 16381) \\
13(124 / 9279) \\
11(62 / 5839) \\
9(94 / 10011)\end{array}$ \\
\hline Total $^{\star}$ & $18(112 / 6086)$ & $26(747 / 28429)$ & $16(367 / 23322)$ & $9(222 / 23762)$ & $18(1448 / 81599)$ \\
\hline \multicolumn{6}{|c|}{ Second birth period } \\
\hline $\begin{array}{l}\text { Tel-Aviv } \\
\text { Haifa } \\
\text { Jerusalem } \\
\text { Tiberias } \\
\text { South }\end{array}$ & $\begin{array}{c}33(72 / 2162) \\
16(34 / 2138) \\
16(20 / 1267) \\
9(8 / 909) \\
17(4 / 240)\end{array}$ & $\begin{array}{l}39(562 / 14264) \\
37(273 / 7353) \\
27(84 / 3138) \\
33(64 / 1918) \\
23(61 / 2600)\end{array}$ & $\begin{array}{l}26(357 / 13896) \\
25(85 / 3466) \\
11(34 / 3003) \\
15(16 / 1034) \\
14(30 / 2121)\end{array}$ & $\begin{array}{c}20(155 / 7594) \\
18(101 / 5761) \\
12(31 / 2572) \\
7(18 / 2695) \\
12(67 / 5812)\end{array}$ & $\begin{array}{l}30(1146 / 37916) \\
26(493 / 18718) \\
17(169 / 9980) \\
16(106 / 6556) \\
15(162 / 10773)\end{array}$ \\
\hline Total* & $20(138 / 6882)$ & $35(1055 / 30079)$ & $22(524 / 23856)$ & $15(375 / 24638)$ & $24(2092 / 85455)$ \\
\hline \multicolumn{6}{|c|}{ Third birth period } \\
\hline $\begin{array}{l}\text { Tel-Aviv } \\
\text { Haifa } \\
\text { Jerusalem } \\
\text { Tiberias } \\
\text { South }\end{array}$ & $\begin{array}{l}50(123 / 2464) \\
22(53 / 2401) \\
22(27 / 1213) \\
15(16 / 1066) \\
23(6 / 258)\end{array}$ & $\begin{array}{l}55(959 / 17336) \\
41(358 / 8772) \\
29(108 / 3732) \\
33(77 / 2368) \\
29(84 / 2927)\end{array}$ & $\begin{array}{l}44(653 / 14998) \\
31(121 / 3866) \\
23(79 / 3390) \\
20(23 / 1153) \\
24(49 / 2069)\end{array}$ & $\begin{array}{l}39(314 / 8013) \\
25(156 / 6302) \\
17(47 / 2730) \\
13(34 / 2650) \\
14(76 / 5507)\end{array}$ & $\begin{array}{l}48(2049 / 42811) \\
32(688 / 21341) \\
24(261 / 11065) \\
21(150 / 7237) \\
20(215 / 10761)\end{array}$ \\
\hline Total $^{\star}$ & $30(235 / 7731)$ & $45(1626 / 36490)$ & $36(937 / 25991)$ & $25(637 / 25570)$ & $36(3435 / 95782)$ \\
\hline \multicolumn{6}{|c|}{ All birth periods } \\
\hline Total $^{\star}$ & $23(485 / 20699)$ & $36(3428 / 94998)$ & $25(1828 / 73169)$ & $17(1234 / 73970)$ & $27(6975 / 262836)$ \\
\hline
\end{tabular}

*The totals include $1.5 \%$ of the conscripts who were not checked in their corresponding regional centre. was $26 \cdot 5 / 1000$ in the male conscripts and $21 \cdot 4 / 1000$ in the females.

Tables I and II show the prevalence of asthma in the subgroups of the male and female conscripts. Asthma was more prevalent in male conscripts in most of the subgroups, and in nearly all of the ethnic and regional groups the prevalence was higher among conscripts who were born later. The prevalence of asthma increased linearly in male conscripts from $18 / 1000$ in the first birth group to $24 / 1000$ in the second group to $36 / 1000$ in the third group, and in female conscripts from $15 / 1000$ to $19 / 1000$ to $29 / 1000$. The conscripts of Western ethnic origin had the highest prevalence of asthma, and those of north African origin had the lowest. The coastal regions had a higher prevalence of asthma than inland regions, the highest rates being observed in the central coastal area, which is the most densely populated and is highly industrialised.

Specialised statistical analyses validated these observations. A logistic model was built by reduction from a model which included all possible indicators for sex, ethnic origin, when born, and area of residence. This full model included 10 variables $(\mathrm{df}=11)$ and was reduced to a model that included seven variables $(\mathrm{df}=8)$ at the cost of 4.8 deviance units (not significant). Further reduction caused a significant loss of information.

Table III shows the results of the reduced logistic model and summarises the influence of different factors on the prevalence of asthma. Male conscripts had a higher risk of being asthmatic than females (adjusted relative risk $1.25(95 \%$ confidence interval $1 \cdot 19$ to $1 \cdot 32)$ ). Conscripts of Western origin had the highest risk of being asthmatic (adjusted risk 1.63 (1.56 to 1.71) relative to those of north African origin) while conscripts of Israeli and Asian origin had a medium risk for asthma (1.20 (1.15 to 1.26$)$ relative to the north African origin). The prevalence of asthma increased over time: conscripts in the first birth group had an adjusted relative risk for asthma of $0.56(0.54$ to $0.59)$ relative to conscripts in the last group while those in the second group had a relative risk of $0.69(0.66$ to $0 \cdot 72$ ). Conscripts from coastal regions had higher risks of being asthmatic, especially those from the Tel-Aviv area (adjusted risk $1.24(1.19$ to 1.30$)$ relative to the north coastal region (Haifa)) while conscripts from inland regions (Tiberias, Jerusalem, and south) had lower risk $(0.67(0.64$ to 0.70$)$ relative to Haifa).

\section{Discussion}

Epidemiological studies of asthma are complicated by the lack of a precise definition of asthma, which prevents agreement about the criteria of diagnosis. Diagnosis of asthma by means of only one method (clinical examination, questionnnaires, lung function, or reactivity) may be misleading. ${ }^{1011}$ The reported prevalence of asthma in surveys of adults has also been affected by selection of the population. In our work the population was unselected and the diagnostic methods are commonly accepted. Primary physicians obtained the subjects' medical history, performed clinical examinations, and referred subjects to a pulmonologist for further examination and lung function tests.

\section{EFFECT OF SEX}

We found an increased prevalence of asthma in male conscripts in all regions of the country. Similar results have been reported with children: a study of asthmatic American children aged from 6 months to 11 years showed an odds ratio of 1.3 for boys versus girls, ${ }^{12}$ and a large British study reported signficantly more boys than girls continuing to support asthma at 16 years old. ${ }^{13}$ However, a Swedish study of children aged 7, 10, and 14 found that the early higher incidence of asthma 
TABLE II-Prevalence of asthma among 180380 female adolescents by time of birth, ethnic origin, and area of residence. Values are prevalence per 1000 subjects (numbers of subjects)

\begin{tabular}{|c|c|c|c|c|c|}
\hline \multirow[b]{2}{*}{$\begin{array}{l}\text { Area of } \\
\text { residence }\end{array}$} & \multicolumn{5}{|c|}{ Ethnic origin } \\
\hline & Israeli & Western & Asian & $\begin{array}{l}\text { North } \\
\text { African }\end{array}$ & Total \\
\hline \multicolumn{6}{|c|}{ First birth period } \\
\hline $\begin{array}{l}\text { Tel-Aviv } \\
\text { Haifa } \\
\text { Jerusalem } \\
\text { Tiberias } \\
\text { South }\end{array}$ & $\begin{array}{c}20(27 / 1371) \\
22(12 / 549) \\
17(10 / 598) \\
5(1 / 192) \\
40(5 / 126)\end{array}$ & $\begin{array}{l}22(258 / 11647) \\
20(102 / 4999) \\
11(15 / 1403) \\
21(25 / 1194) \\
13(24 / 1876)\end{array}$ & $\begin{array}{c}13(130 / 10183) \\
11(20 / 1758) \\
8(13 / 1571) \\
9(6 / 643) \\
14(16 / 1176)\end{array}$ & $\begin{array}{c}14(75 / 5365) \\
10(30 / 3119) \\
5(6 / 1150) \\
2(3 / 1236) \\
5(14 / 3095)\end{array}$ & $\begin{array}{c}17(490 / 28566) \\
16(164 / 10425) \\
9(44 / 4722) \\
11(35 / 3265) \\
9(59 / 6273)\end{array}$ \\
\hline Total ${ }^{\star}$ & $19(55 / 2836)$ & $20(424 / 21127)$ & $12(185 / 15332)$ & $9(128 / 13969)$ & $15(792 / 53264)$ \\
\hline \multicolumn{6}{|c|}{ Second birth period } \\
\hline $\begin{array}{l}\text { Tel-Aviv } \\
\text { Haifa } \\
\text { Jerusalem } \\
\text { Tiberias } \\
\text { South }\end{array}$ & $\begin{array}{l}17(28 / 1633) \\
18(12 / 653) \\
12(8 / 646) \\
12(3 / 254) \\
33(4 / 123)\end{array}$ & $\begin{array}{l}27(330 / 12074) \\
25(138 / 5560) \\
16(27 / 1658) \\
17(28 / 1644) \\
22(45 / 2068)\end{array}$ & $\begin{array}{l}18(196 / 10604) \\
17(37 / 2224) \\
8(15 / 1832) \\
16(12 / 754) \\
17(21 / 1267)\end{array}$ & $\begin{array}{c}18(101 / 5695) \\
12(43 / 3715) \\
6(9 / 1415) \\
8(12 / 1588) \\
8(29 / 3516)\end{array}$ & $\begin{array}{l}22(655 / 30006) \\
19(230 / 12152) \\
11(59 / 5551) \\
13(55 / 4240) \\
14(99 / 6974)\end{array}$ \\
\hline Total $^{\star}$ & $17(55 / 3316)$ & $25(569 / 23057)$ & $17(281 / 16715)$ & $12(194 / 15948)$ & $19(1099 / 59036)$ \\
\hline \multicolumn{6}{|c|}{ Third birth period } \\
\hline $\begin{array}{l}\text { Tel-Aviv } \\
\text { Haifa } \\
\text { Jerusalem } \\
\text { Tiberias } \\
\text { South }\end{array}$ & $\begin{array}{l}37(73 / 1960) \\
33(26 / 784) \\
18(12 / 669) \\
26(9 / 340) \\
29(5 / 173)\end{array}$ & $\begin{array}{l}37(519 / 14068) \\
36(261 / 7236) \\
22(46 / 2101) \\
25(53 / 2135) \\
26(62 / 2373)\end{array}$ & $\begin{array}{l}29(303 / 10599) \\
29(77 / 2700) \\
16(35 / 2168) \\
17(14 / 814) \\
15(21 / 1443)\end{array}$ & $\begin{array}{c}33(179 / 5432) \\
30(121 / 4069) \\
17(27 / 1631) \\
9(14 / 1562) \\
10(38 / 3657)\end{array}$ & $\begin{array}{l}34(1074 / 32059) \\
33(485 / 14789) \\
18(120 / 6569) \\
19(90 / 4851) \\
16(126 / 7646)\end{array}$ \\
\hline Total $^{\star}$ & $32(129 / 4049)$ & $34(965 / 28628)$ & $26(483 / 18570)$ & $23(393 / 16803)$ & $29(1970 / 68050)$ \\
\hline \multicolumn{6}{|c|}{ All birth periods } \\
\hline Total* & $23(239 / 10201)$ & $27(1958 / 72812)$ & $19(949 / 50617)$ & $15(715 / 46720)$ & $21(3861 / 180350)$ \\
\hline
\end{tabular}

*The totals include $1.5 \%$ of the conscripts who were not checked in their corresponding regional centre.

TABLE III-Relative risk of asthma associated with various factors for Israeli adolescents

\begin{tabular}{|c|c|c|}
\hline Factor & $\beta(\mathrm{SE})$ & $\begin{array}{l}\text { Standardised risk of asthma } \\
\text { ( } 95 \% \text { confidence interval) }\end{array}$ \\
\hline \multicolumn{3}{|l|}{ Sex: } \\
\hline Male & $0.026(0.018)$ & $1.25(1.19 \text { to } 1.32)^{\star}$ \\
\hline \multicolumn{3}{|l|}{ Ethnic origin: } \\
\hline Israeli or Asian & $0 \cdot 186(0.025)$ & $1.20(1.15$ to 1.26$) \dagger$ \\
\hline Western & $0.492(0.0236)$ & $1.63(1.56$ to 1.71$) \dagger$ \\
\hline \multicolumn{3}{|l|}{ Time of birth: } \\
\hline First period & $-0.574(0.0226)$ & $0.56(0.54$ to 0.59$) \ddagger$ \\
\hline Second period & $-0.370(0.0207)$ & $0.69(0.66$ to 0.72$) \ddagger$ \\
\hline \multicolumn{3}{|l|}{ Area of residence: } \\
\hline Tel-Aviv region & $0.219(0.021)$ & $1.24(1.19$ to 1.30$)$ \\
\hline Tiberias, south, or Jerusalem region & $-0.403(0.0262)$ & $0.67(0.64$ to 0.70$) \oint$ \\
\hline
\end{tabular}

in boys gradually disappeared during childhood, ${ }^{14}$ and among Medicaid patients in Michigan asthma was more prevalent in women than men even though it was more prevalent in boys than girls. ${ }^{15} \mathrm{~A}$ study of the epidemiology of asthma in the United States over the past 20 years showed asthma to be more prevalent among males, those living below the poverty level, persons living in the south and west, and black subjects, but the differences were not significant. ${ }^{16}$

EFFECT OF TIME

We found that the prevalence of asthma increased linearly with time in male and female conscripts. This supports the increasing prevalence of asthma reported in industrialised countries. ${ }^{11718}$ Many studies have reported an increasing prevalence in children from 1960 to 1980: a representative sample of children in English primary schools showed a yearly increase in asthma ${ }^{4}$; in the United States the prevalence though not the severity of asthma increased in children aged under 17 during $1964-80,{ }^{16}$ and between 1976 and 1980 the prevalence increased among children aged 6-11 from $4.8 \%$ to $7 \cdot 6 \%{ }^{18}$; asthma increased from $4 \%$ in 1973 to $9 \%$ in 1988 among 12 year old children in an area of South Wales ${ }^{19}$; in two epidemiological surveys in Taiwan asthma increased from $1.3 \%$ in 1974 to $5.07 \%$ in $1985^{20}$; and a questionnaire survey of parents of children from Nottingham primary schools found a prevalence of reported asthma of $6 \%$ in 1985 and $8.9 \%$ in 1988, but the prevalence of treatment for asthma and wheeze did not change. ${ }^{21}$

A similar increase in prevalence has been reported in adults: in Medicaid patients in Michigan the prevalence of asthma increased from $2.0 \%$ in 1980 to $2.8 \%$ in $1986^{15}$; in Finnish young men the prevalence of asthma increased linearly from $0.3 \%$ in 1966 to $1.8 \%$ in $1989^{6}$; in large surveys in England and Wales in 1970-1 and 1981-2 the prevalence of asthma increased from $1 \cdot 2 \%$ to $2.1 \%$ in men and from $0.9 \%$ to $1.6 \%$ in women ${ }^{22}$; and in Swedish conscripts the prevalence of asthma increased during $1971-81$ from $1.9 \%$ to $2.9 \% .^{5}$ In Denmark, however, asthma does not appear to be increasing in prevalence. ${ }^{23}$ Studies in Israel indicate an increase of asthma in the adolescent population ${ }^{24}$ and an increase in asthma mortality. ${ }^{25}$ In a recent survey of all 17 year old males in one region of Israel in 1986 and 1990 the prevalence of asthma increased from $5 \%$ to $5.9 \%{ }^{26}$ These results are similar to ours $(4 \cdot 8 \%$ in the period including 1986) and demonstrate the continuing increase in the prevalence of asthma after the end of our study.

\section{EFFECT OF ETHNIC ORIGIN}

Our study population consisted of conscripts of four different ethnic origins. We found that Israelis of Western origin had the highest prevalence of asthma while those of north African origin had the lowest. Some studies have reported a higher prevalence of asthma in black American children relative to white American children. ${ }^{316}{ }^{18}$ Mortality and rates of hospital admission for asthma were higher in Maoris and Pacific Islander children than in European children, ${ }^{27}$ but the prevalence of asthma was not different. ${ }^{27}{ }^{28}$ In a large sample of white and Mexican Americans in Arizona ethnic origin was not associated with prevalence of symptoms of asthma or impaired lung function..$^{29}$ Some studies have reported differences of prevalence between whites of different origin: a hospital based study in Canada of asthmatic patients suggested that north eastern Europeans and Scandinavians were more likely to develop asthma, ${ }^{30}$ and Saskatchewan grain workers of British ancestry had a significantly greater prevalence of airway obstruction (odds ratio $3 \cdot 2$ ) than eastern European workers. ${ }^{31}$

\section{REGIONAL EFFECT}

In our study a high risk for active asthma was found in coastal regions, possibly due to the dampness and the low altitude. Increasing altitude generates a gradual decrease in dermatophagoides, thus explaining both the clinical improvement in asthmatics living at high altitude and the lower prevalence of asthma in popu-

\section{Public health implications}

- The prevalence of asthma is increasing in industrialised countries, and air pollution has been suggested as a possible cause

- The medical records of more than 400000 Israeli conscripts aged 17-18 who were born over a period of nine years were studied for presence of asthma

- The prevalence of asthma increased over time and was higher in males, in conscripts whose families came from Western countries, and in those living in the most industrialised coastal region of Israel

- Asthma is becoming more prevalent in Israel as in other industrialised countries 
lations born and living there. ${ }^{32}$ The highest prevalence of asthma was found in the central coastal region, which is the most populated and industrialised part of the country. Here an effect of pollution is suspected, in agreement with the prevailing view that environmental factors may at least partially explain the rising prevalence of asthma. In western Europe rapid variations in air pollution act as a trigger for asthma attacks, but the concentrations of air pollutants currently prevailing in western Europe do not induce a higher incidence of asthma.

\section{POTENTIAL BIAS}

In our study the prevalence of asthma among males could have been biased, firstly, by conscripts who wished to serve in field units not revealing their history of asthma and, secondly, by conscripts falsely claiming that they suffered from asthma in an attempt to avoid combat service. The second bias was ruled out by the second physical examination by a pulmonologist, which included lung function tests.

1 Anderson HR, Bland JM, Patel S, Paerham C. The natural history of asthm in childhood. $f$ Epidemiol Community Health 1986;40:121-9. Petersdoof RG, Martin JB, Fauci AS, et al. Harrison's principles of interne medicine. 12th ed. New York: McGraw-Hill, 1991:1047-53.

3 Witzman M, Gortmaker S, Sobol A. Racial, social, and environmental risks fo childhood asthma. Am $\mathcal{F}$ Dis Child 1990;144:1189-94.

4 Burney PG, Chinn S, Rona RJ. Has the prevalence of asthma increased in children? Evidence from the national study of health and growth 1973-86. $B M 7$ 1990;300:1306-10.

5 Aberg N. Asthma and allergic rhinitis in Swedish conscripts. Clin Exp Allergy 1989;19:59-63.

6 Haahtela T, Lindholm H, Bjorksten F, Koskenvuo K, Laitinen LA Prevalence of asthma in Finnish young men $B M 7$ 1990;301:266-8,

7 Kark JD, Kedem R, Revach M. Medical examination of Israeli 17 year old before military service as a national resources for health information. Isr F Med Sci 1986;22:318-25. and applied probability. Cambridge: Cambridge University Press, 1985. 6.04. Cary, NC: SAS Institute, 1990. (Technical report p-200.)

10 Enarson DA, Vedal S, Schulzer M, Dybuncio A, Chan-Yaung M. Asthma, asthma like symptoms, chronic bronchitis, and the degree of bronchia hyperresponsiveness in epidemiologic surveys. Am Rev Respir Dis 1987;136: 613-7.

\section{Drivers who defy the law}

\section{J S Mars}

\section{Cardiff CF4 4AQ}

JS Mars, registrar in ophthalmology

$B M \mathcal{F} 1993 ; 307: 844-5$
2 McFadden ER Jr. Asthma. In: Wilson JD, Braunwald E, Isselbacher $\mathrm{KJ}$

8 McCullagh P, Nelder JA. Generalized linear models-Monographs on statistic

9 SAS Institute. SAS/STAT software: CALIS and logistic procedures. Release

11 Halfon N, Newadecher PW. Trends in hospitalization for acute childhood asthma 1970-1984. Am f Public Health 1986;67:1308-11.

12 Schwaetz J, Gold D, Dockery DW, Weiss ST, Speizer FE. Predictors of asthma and persistent wheeze in a national sample of children in the United States. Association with social class, perinatal events, and race. Am Rev Respir Dis 1990;142:555-62.

13 Kaplan BA, Mascie Taylor CG. Asthma and wheezy bronchitis in adolescents: biosocial correlates. $\mathcal{F}$ Asthma 1988;25:125-9.

14 Aberg N, Engstrom I. Natural history of allergic diseases in children. Acta Paediatr Scand 1990;79:206-11.

15 Gerstman BB, Bosco LA, Tomita DK, Gross TP, Shaw MM. Prevalence and treatment of asthma in the Michigan Medicaid patient population younger than 45 years, 1980-1986. 7 Allergy Clin Immunol 1989;83:1032-9.

16 Evans R 3rd, Mullally DI, Wilson RW, Gergen PJ. National trends in the morbidity and mortality of asthma in the US. Prevalence, hospitalization and death from asthma over two decades: 1965-1984. Chest 1987;91 (suppl 6):65-74S.

17 Burr ML. Is asthma increasing? $\mathcal{F}$ Epidemiol Community Health 1987;41:185-9.

17 Burr ML. Is asthma increasing? $\mathcal{F}$ Epidemiol Community Health 1987;41:185-9. Gergan PJ, Mullaly DL, Evans R 3rd. National survey of prevalence of asth
among children in the United States 1976-1980. Paediatrics 1988;81:1-7.

19 Burr ML, Butland BK, King S, Vaugham WE. Changes in asthma prevalence: two surveys 15 years apart. Arch Dis Child 1989;64:1452-6.

$20 \mathrm{Hsieh} \mathrm{KH}$, Shen JJ. Prevalence of childhood asthma in Taipei, Taiwan, and other Asian Pacific countries. I Asthma 1988;25:73-82.

21 Hill $R$, Williams J, Tattersfield A, Briton J. Change in use of asthma as a diagnostic label for wheezing illness in schoolchildren. $B M \mathcal{f} 1989 ; 299: 898$.

22 Fleming DM, Crombie DL. Prevalence of asthma and hay fever in England and Wales. $B M$ F 1987;294:279-83.

23 Pedersen PA, Weeke ER. Epidemiology of asthma in Denmark. Chest 1987;91 (suppl 6):107-14S.

24 Brook U. Is prevalence of adolescent asthma increasing in Israel? Harefuah 1991;120:539-42.

25 Schwartz YA, Kivity S, Greif J, Topilsky $M$. Is there a change in asthme mortality in Israel? Ann Allergy 1990;65:105-8.

26 Aurbach I, Springer S, Godfrey S. Total population survey of the frequency and severity of asthma in 17 year old boys in an urban area in Israel. Thorax 1993;48:139-41.

27 Mitchell EA. Racial inequalities in childhood asthma. Soc Sci Med 1991;32. 831-6.

28 Pattemore PK, Asher MI, Harrison AC, Mitchell EA, Rea HH, Stewart AW. Ethnic differences in prevalence of asthma symptoms and bronchial hyperresponsiveness in New Zealand schoolchildren. Thorax 1989;44: $168-76$.

29 Di Pede C, Viegi G, Quackenboss J, Boyer PP, Lebowitz MD. Respirator symptoms and risk factors in an Arizona population sample of Anglo and Mexican American whites. Chest 1991;99:916-22.

30 Horne SL, Cockcroft DW. Ethnicity as a possible factor contributing to the development of chronic airflow limitation and asthma. Clin Invest Med development 199 ; $1333-8$.

31 Horne SL, To T, Cockcroft DW. Ethnic differences in the prevalence of pulmonary airflow obstruction among grain workers. Chest 1989;95:992-6. 32 Charpin D, Vervloet D, Charpin J. Epidemiology of asthma in western Europe. Allergy 1988;43:481-92.

(Accepted 20 Fuly 1993)

insurers and the Driver and Vehicle Licensing Agency. Three months later they were reviewed.

A total of 189 patients (38\%) were identified as drivers. Twenty eight drivers had a visual acuity of $6 / 18$ or worse, and 27 were reviewed three months later. There was no significant difference in age or sex between drivers with inadequate vision and drivers with satisfactory vision. The commonest cause of impaired vision was cataract (10 drivers; 37\%), followed by macular degeneration (six drivers, $22 \%$ ); other causes included glaucoma, keratoconus, myopic degeneration, and panuveitis.

At review all 27 patients still had a visual acuity of $6 / 18$ or worse. A total of 16 of the 27 admitted to still driving despite the clear advice they had been given. No patient who continued to drive and only five of those who had ceased had informed their insurers or the licensing agency. There was no significant difference in age, sex, diagnosis, or visual acuity between those drivers with poor vision who continued to drive and those who had stopped.

Subjects, methods, and results

From April 1992, 500 consecutive patients aged 17 or over attending ophthalmic outpatient clinics were assessed. Their age, sex, visual acuity, diagnosis, and driving status were recorded.

Drivers who had a binocular best corrected visual acuity of $6 / 18$ Snellen or worse were identified as clearly failing to meet the visual standard. They were advised not to drive and to report the situation to their
Sex, age, and vision of drivers attending an ophthalmology clinic

\begin{tabular}{lrrrrrr}
\hline & \multicolumn{2}{c}{ Sex } & & \multicolumn{2}{c}{ Age } \\
\cline { 2 - 3 } \cline { 5 - 6 } \cline { 5 - 6 } & Men & Women & & Median & Range \\
\hline Study group $(n-500)$ & 255 & 245 & & 68 & $17-95$ \\
Drivers $(\mathrm{n}=189)$ & 116 & 73 & & 60 & $17-93$ \\
Inadequate vision $(\mathrm{n}=27)$ & 17 & 10 & & 62 & $22-93$ \\
Continuing to drive $(\mathrm{n}=16)$ & 11 & 5 & & 62 & $22-93$ \\
Stopping driving $(\mathrm{n}=11)$ & 6 & 5 & & 64 & $47-85$ \\
\hline
\end{tabular}

